\title{
DILEMAS SOBRE LA NATURALEZA JURÍDICA Y EL FUNDAMENTO DEL "NON BIS IN IDEM" EN ESPAÑA Y MÉXICO
}

\author{
Problems about the legal nature and the fundament of "non bis in idem" \\ in Spain in México
}

Liliana HERNÁNDEZ MENDOZA*

Sumario:

I. Naturaleza jurídica II. Fundamento del non bis in idem y cosa juzgada

\begin{abstract}
Resumen: No ha sido sencillo aclarar los dilemas acerca de la naturaleza jurídica y el fundamento del non bis in idem, ya que a lo largo de la historia se han planteado diversas posturas que implican un análisis exhaustivo sobre estos temas, por ejemplo, respecto a la naturaleza jurídica se define como un principio general de Derecho y no como una regla jurídica y en cuanto al fundamento éste comprende una serie de principios como son el de legalidad, proporcionalidad y seguridad jurídica todos ellos unidos entre si conforman el fundamento, no obstante es importante hacer mención que el non bis in idem se relaciona con la cosa juzgada sin que ésta figura jurídica sea parte del fundamento.
\end{abstract}

Palabras clave: Naturaleza jurídica, fundamento del principio non bis in idem y cosa juzgada

Abstract: It has not been easy to clarify the dilemmas about the legal nature and basis of the non bis in idem, since throughout history have raised various positions involving an exhaustive analysis of these issues, for example concerning the legal nature is defined as a general principle of law and not as a legal rule as to the basis it comprises a set of principles as are the legality, proportionality and legal certainty all joined together form the foundation, however it is important to mention that the non bis in idem relates to the res judicata without this legal concept is part of the foundation

Keyword: Legal nature, the foundation of the non bis in idem and res judicata

\section{Introducción}

La naturaleza jurídica y el fundamento del non bis in idem han sido objeto de controversia en la doctrina científica y jurisprudencial, ya que ambas figuras a lo largo de la historia tienen diversas tesis que traen como consecuencia que no exista coincidencia respecto de si dicho principio configura un regla jurídica o un principio general de Derecho; en el mismo sentido se habla del fundamento, ya que no se tiene unanimidad respecto a qué principios lo conforman, pero recordemos que representa hoy una de las más importantes garantías constitucionales de las sanciones, para lo cual fue indispensable su estudio sobre dichos aspectos.

\footnotetext{
* Doctora en Derecho por la Universidad Complutense de Madrid, España. Diploma de Estudios Avanzados por la misma Institución. Lic. en Derecho por la Universidad de Guanajuato.
} 


\section{Naturaleza jurídica}

Respecto a la naturaleza jurídica del non bis in idem, no existe unanimidad en reconocerlo como un principio general debido a los dilemas que existen entre las diversas posturas, ya que para algunos autores es una regla jurídica que aduce un calificativo de principio, pero que no se encontraba establecida ni en las normas y mucho menos en la constitución lo que representa para ellos una regla jurídica no positivizada en una norma1.

Para otro sector doctrinal, el non bis in idem sí se configura como un principio general de Derecho $^{2}$, ya que constituye valores básicos del ordenamiento jurídico a lo que García de Enterría denomina los valores que constituyen convicciones ético-jurídicas fundamentales de una comunidad $[\ldots]^{3}$.

Por ende, este aforismo latino es un principio general de derecho que tiene un carácter informador del ordenamiento jurídico, tan es así, que lo estipula el artículo 1.4 del Código Civil español, pues informa sobre las soluciones a los problemas que se planteen sobre el mismo. Otro argumento es la relevancia constitucional que le otorga el artículo 5.1 de la LOPJ en España, en el sentido de contener los criterios para interpretar y aplicar las normas escritas. Pero, es posible afirmar que también contiene reglas jurídicas respecto de la vertiente material y procesal, como imponer dos sanciones sobre el mismo ilícito cuando exista la identidad de sujeto, hecho y fundamento, así como la prohibición doble enjuiciamiento, pero estas reglas no implican que deje de ser un principio, ya que siempre contendrá primero los valores básicos de un ordenamiento jurídico.

En México se considera, también, un principio aunque no esté estipulado de manera textual en su artículo 23 de la Constitución Política de los Estados Unidos Mexicanos, pero sí se estipula por ejemplo en la Ley de Justicia para adolescentes del Estado de Coahuila de Zaragoza, el cual menciona en su

artículo 20 (principio non bis in idem): Ningún adolescente podrá ser juzgado más de una vez por la misma conducta. Si en la secuela de un proceso apareciere que se ha cometido una

\footnotetext{
${ }^{1}$ Nieto, Alejandro (2012), Derecho administrativo sancionador, $5^{\mathrm{a}}$ ed. TECNOS, Madrid, pp. 438-439. Vid. González Pérez, Jesús., y González Navarro (2007), Francisco, Comentarios a la Ley de Régimen Jurídico de las Administraciones Públicas y del Procedimiento Administrativo Común, vol. II, $4^{\mathrm{a}}$ ed. Civitas, Madrid, también opina que el non bis in idem es una regla jurídica, p. 3028.

2 Santamaría Pastor, Juan Alfonso (2009), Principios de derecho administrativo general, Vol. II, $2^{\mathrm{a}}$ ed., IUSTEL, Madrid, pp. 405-408; Benlloch Petit, Guillermo (1998), "El principio de non bis in idem en las relaciones entre el Derecho Penal y el Derecho disciplinario", en: Revista del Poder Judicial, Consejo General del Poder Judicial, España, núm.51, p. 312; y CARretero SÁncheZ, Adolfo (1995), Derecho administrativo sancionador, $2^{\mathrm{a}}$ ed., EDERSA, Madrid, p. 191; Queralt Joan Josep (1992), El principio non bis in ídem, TECNOS, Madrid, p. 9; Trayter Jiménez, Juan Manuel (1991), "Sanción penal-sanción administrativa: el principio "non bis in idem” en la jurisprudencia”, en Poder Judicial, núm. 22, p. 115; Del Rey Guanter, Salvador (199o), Potestad sancionadora de la Administración y jurisdicción penal en el orden social, Ministerio de Trabajo y Seguridad Social, Madrid, pp. 111-116; SANZ GANDÁSEGUI, Francisco (1985), La potestad sancionadora de la Administración. La Constitución española y el Tribunal Constitucional, EDERSA, Madrid, p. 129; GARberí Llobregat, José (1989), La aplicación de los derechos y garantías constitucionales a la potestad y al procedimiento administrativo sancionador: (Doctrina del Tribunal Constitucional y reforma legislativa), Triyium, Madrid, p. 149; Alarcón Sotomayor Lucía, El non bis in idem como principio general del derecho administrativo, en SANTAMARÍA PASTOR, Juan Alfonso (2010), (dir.), Principios Jurídicos del derecho administrativo, La Ley, Madrid, , pp. 419-423. La jurisprudencia se inclina también por esta línea y así se establece hasta la fecha en siguientes sentencias SSTS 221/2016, de 16 de marzo (Ref. Iustel: $\$ 360718), 506 / 2015$, de 27 de julio (Ref. Iustel: $\$ 360451$ ), 1996/2014, de 2 de junio de 2015 (Ref. Iustel: $\$ 360420)$, todas ellas denominan al non bis in idem como un principio y no como una regla jurídica.

3 García De Enterría, Eduardo, y Fernández Rodríguez, Tomás Ramón (2006), “Curso de derecho administrativo", Tomo I, $13^{\text {a }}$ ed. Civitas, Madrid, p. 85.
} 
conducta tipificada como delito por las leyes penales distinta de la que se persigue, deberá ser objeto de la integración de una investigación por separado, sin perjuicio de que después pueda decretarse la acumulación, si fuere conducente".

Además la jurisprudencia reitera que el non bis in ídem se configura como principio general de Derecho ${ }^{4}$.

\section{Fundamento}

En cuanto al fundamento del principio non bis in idem en España, existen diversos dilemas que se analizarán enseguida, pero cabe señalar primero que el Tribunal Constitucional lo reconoce como un derecho fundamental, el cual deviene de la sentencia 2/1981, de 30 de enero, donde se indica que encuentra su fundamento en los principios de legalidad y tipicidad de las infracciones o sanciones, erigiéndose en garantía de los derechos fundamentales del ciudadano frente a las arbitrariedades del poder público ${ }^{5}$..

Si bien el principio no se encuentra recogido expresamente en los artículos 14 al 30 de la Constitución española, donde se reconocen los derechos y libertades susceptibles de amparo (artículo 53, número 2, de la Constitución, es una de las consecuencias más importantes que se extraen de la Jurisprudencia constitucional y, 41 de la LOTC), no por ello cabe silenciar que, como entendieron los parlamentarios en la Comisión de Asuntos Constitucionales y Libertades del Congreso al prescindir de él en la redacción del artículo 9 del Anteproyecto de Constitución, va intimamente unido a los principios de legalidad y tipicidad de las infracciones recogidos principalmente en el artículo 25 de la Constitución ${ }^{6}$. Se destacan los siguientes principios como el fundamento del non bis in idem.

\subsection{Principio de legalidad}

Para un sector doctrinal, el principio de legalidad comprende el fundamento del non bis in idem ya que representa los límites que se establecen en cada norma jurídica, pues las autoridades no pueden actuar por iniciativa propia sino ejecutando el contenido de la ley ${ }^{7}$. Además opera como

${ }^{4}$ Las siguientes tesis aisladas hacen alusión al non bis in ídem como principio en sus diferentes temas, por ejemplo la tesis de rubro: Agravantes. No son violatorias del principio no bis in idem, de registro 16194; non bis in idem. Violación al principio de, cuyo registro es 195393; non bis in idem. Violación no configurada al principio de con número de registro: 234951.

5 Todas estas sentencias y autos aluden a la garantía non bis in idem como un derecho fundamental, ATC $389 /$ 1988, de 24 de marzo; ATC 648/ 1988, de 23 de mayo; STC 66/1986, de 23 de mayo; STC 94/1986, de 8 de julio; STC 107/1989, de 8 de junio; STC 154/1990, de 15 de octubre; STC 234/1991, de 10 de diciembre; STC 204/ 1996, de 16 de diciembre; STC 221/1997, de 4 de diciembre; STC 2/2003, de 16 de enero; STC 229/2003, de 18 de diciembre; ATC 239/2003 de 14 de julio; ATC 277/2003, de 25 de julio; ATC 357/2003, de 10 de noviembre; ATC 141/2004, de 26 de abril; STC 180/2004, de 2 de noviembre; STC 188/2005 de 7 de julio; STC 334/2005, de 20 de diciembre; STC 48/2007, de 12 de marzo; STC 91/2008, de 21 de julio. En similar sentido hace referencia al non bis in idem como un principio la STS de 27 de enero de 2012 (Ref. IUSTEL: \$345788).

6 Vid. García De Enterría, Eduardo (2006), La constitución como norma y el tribunal constitucional, 4 ed. Aranzadi, Madrid, p. 260.

7 Dicho contenido de Ley (Beccaria, 1983) está hecho por el poder legislativo que representa la soberanía popular y es el único legitimado para establecer cuáles son las conductas que deben ser consideradas ilícitas y qué sanciones se han de imponer sobre ellas, frenando los posibles abusos de los demás poderes. En este sentido BECCARIA, Cesare, De los delitos y las penas, (J. A. de las Casas, Traductor), Alianza, Buenos Aires, 1983, apunta que sólo las leyes pueden decretar las penas de los delitos y esta autoridad debe residir en el legislador [...], p. 29. 
una cobertura legal previa a la realización del hecho ${ }^{8}$, así que imponer dos sanciones al mismo sujeto por un mismo hecho y fundamento vulneraría el principio non bis in idem de acuerdo a lo establecido en el artículo 25.1 de la Constitución española y 23 de la constitución mexicana.

Por otro lado, el non bis in idem dejaría de tener un contenido garantista si un mismo hecho, y por igual fundamento, pudiese ser objeto de una nueva sanción al mismo sujeto, lo que comportaría un punición desproporcionada de la conducta ilícita. La finalidad de las normas es prevenir los actos ilícitos y, por tanto, no tendría sentido la imposición de dos o más sanciones que no se encuentren reguladas legalmente, ya que esto produciría una violación al non bis in idem ${ }^{9}$.

García de Enterria, menciona que la vigencia del principio se propicia directamente desde la garantía criminal del principio de legalidad, en el sentido de asegurar que la realización de un hecho no se conectará a calificaciones plurales". El autor considera que la inclusión del "non bis in idem" en los principios de legalidad y tipicidad que se enuncian en el artículo 25 le parece clara $^{11}$.

Por ende, el principio de legalidad se concibe en la determinación de conductas prohibidas, así como también implica la derivación de consecuencias jurídicas que de su realización se desprenden tipos penales o administrativos.

En este sentido, se afirma que las sanciones asignadas a cada ilícito expresan el desvalor que el ordenamiento jurídico atribuye a una determinada conducta y se impone con pretensión de agotar el desvalor del hecho. De esto se infiere que la pretensión de volver a sancionar el ilícito cuando concurre la triple identidad (sujeto, hecho y fundamento) infringe el principio non bis in idem, pues supone rebasar los límites de la sanción prefijados. Así resultaría evidente una

\footnotetext{
${ }^{8}$ Vid. Zugaldia Espinar, José Miguel (2004), El Derecho penal. Parte general, Tirant lo Blanch, Valencia, señala que el principio de legalidad contiene la exigencia de la lex praevia cuyo contenido especifica que la ley sea anterior al hecho sancionado. La conducta puede ser considerada delito y resultar penada si está prevista como tal y con las correspondientes consecuencias jurídicas en una ley vigente en el momento en que se realiza la cuestión, pp. 237-239. Vid sobre las garantías del principio de legalidad Trayter, Joan Manuel (1992), Manual de derecho disciplinario de los funcionarios públicos, Marcial Pons, Madrid, pp. 111-112; en similar sentido PULIDo QueCEDo, Manuel (2009), "Lex certa, sanciones administrativas y remisiones legales", en: Revista Aranzadi Doctrinal, Aranzadi, España, núm. 4, p. 1; LAscuraín Sánchez, Juan Antonio (2009), "Sólo penas legales, precisas y previas: El derecho a la legalidad penal en la jurisprudencia constitucional”, en: Cuadernos Aranzadi del Tribunal Constitucional, Aranzadi, España, núm. 23, pp. 4-192; SAlás Darrocha, J. T. (2005), "Derecho fundamental a la legalidad penal: Jurisprudencia Constitucional y consideraciones críticas”, en Sentencias del TSJ Y AP y otros Tribunales, núm. 10, p. 3. En similares términos se presenta una reiterada jurisprudencia como son las SSTS de 12 de noviembre de 2009 (Ref. IUSTEL: $\$ 298567$ ); de 22 de mayo de 2009 (Ref. IUSTEL: \$290877); de 28 de mayo de 2009 (Ref. IUSTEL: \$295211); la SSTC 283/2006 de 9 de octubre; las SSTC 24/2005 de 26 de febrero; 218/2005 de 12 de septiembre; 297/2005 de 21 de noviembre; 242/2005 de 10 de octubre; 100/2003 de 2 de junio; 270/1994, de 17 de octubre; 53/1994 de 24 de febrero; 116/1993 de 29 de marzo; 127/1990 5 de julio, 133/1987 de 21 julio.

${ }^{9}$ Cano Campos, Tomás (2003), "La suspensión de las autorizaciones administrativas para conducir en las infracciones sancionadas por autoridades distintas de las del Estado", en: Revista Española de Derecho Administrativo, Civitas, Madrid, núm. 120, agrega lo siguiente: El fundamento de esa vertiente del non bis in idem demuestra claramente el alcance de la prohibición, un fundamento que no es otro, a pesar de numerosas voces discrepantes, que el principio de legalidad consagrado en el artículo 25.1 de la CE”, p. 608.

${ }^{10}$ Garcia De Enterria, Eduardo y Fernández Rodríguez, Tomás Ramón (1981), La incidencia de la Constitución sobre la potestad sancionadora de la administración: dos importantes sentencias del Tribunal Constitucional, en: Revista Española de Derecho Administrativo, Civitas, Madrid, núm. 29, p. 362.

${ }^{11}$ García De Enterria, Eduardo, "La incidencia de la Constitución sobre la potestad sancionadora de la administración: dos importantes sentencias del Tribunal Constitucional”, pp. 361 y 362.
} 
demasía del poder punitivo por parte del Estado frente a los ciudadanos, pues no tienen por qué verse afectados, si una sanción única y plural es asignada a cada ilícito.

Como decimos son varios los autores que se inclinan en establecer que el principio de legalidad es el fundamento del non bis in idem ${ }^{12}$. La jurisprudencia del Tribunal Constitucional establece que el fundamento del non bis in idem es el principio de legalidad y tipicidad ${ }^{13}$, además de otros principios que a continuación se explicarán.

\subsection{Principio de proporcionalidad}

Otro dilema se presenta en el sector doctrinal, ya que para algunos autores el fundamento del non bis in idem se encuentra en el principio de proporcionalidad, debido a que toda sanción debe ajustarse a las circunstancias del caso concreto, pues de lo contrario se produciría una sanción desproporcionada y contraria a Derecho ${ }^{14}$.

La vertiente material de non bis in idem no sólo se conecta con el principio de legalidad y tipicidad, sino que también con el principio de proporcionalidad. La Constitución española y

\footnotetext{
${ }^{12}$ Algunos de los autores mencionados como Gómez Tomillo, Manuel y Sanz Rubiales, Iñigo (2010), Derecho administrativo sancionador. Teoría general y práctica del Derecho penal y administrativo, $2^{\mathrm{a}}$ ed. Aranzadi, Madrid, p. 206; De León Villaba, Francisco Javier, Acumulación de sanciones penales y administrativas, p. 446; García Albero, Ramón, Non bis in idem material y concurso de leyes penales, CEDECS, Barcelona, 1995, menciona que la manifestación concreta del "non bis in idem" — se refiere a la prohibición de doble sanción por la misma infracción- puede explicarse desde el significado esencial del principio de legalidad, también en relación con el Derecho Penal y el sancionador administrativo", pp. 90-91; Zugaldia Espinar, José Miguel, El Derecho penal. Parte general, pp. 234-240; Del Rey Guanter Salvador, Potestad sancionadora de la Administración y jurisdicción penal en el orden social, p. 123; NAVARro Cardoso, Fernando, Infracción administrativa y delito: límites a la intervención del Derecho Penal, COLEX, Madrid, 2001, p. 36; SuAy Rincón, José, Sanciones administrativas, Publicaciones del Real Colegio de España, Bolonia, 1989, p. 179 Lozano Suárez, L. M., El principio non bis in idem: Colisión entre derecho penal y derecho administrativo sancionador, en: Revista de Derecho Penal, LEX NOVA, España, núm. 15, 2005, señala que se acepta que el non bis in idem, integra un principio general de Derecho, si bien, dado su engarce con el principio de legalidad del artículo 25.1 de la Constitución, puede ser considerado igualmente un derecho fundamental susceptible de ser protegido a través de recurso de amparo ante el Tribunal Constitucional, p. 57; En el mismo sentido, Díaz Pita, María Del Mar, "Informe sobre el principio non bis in idem y la concurrencia de jurisdicciones entre los Tribunales Penales Españoles y los Tribunales Penales Internacionales", en Revue International de Droit Pénal, núm. correspondiente al $3^{\circ}$ y $4^{\circ}$ trimestre de 2002, menciona el principio non bis in idem, se configura como consecuencia necesaria del principio de legalidad y taxatividad de las leyes penales y sancionadoras restrictivas de derechos, p. 873 .

${ }^{13}$ El Tribunal Constitucional desde la sentencia 2/1981, de 30 de enero, en su fundamento jurídico $4^{\circ}$ perfiló las bases del non bis in idem y estableció su fundamentación constitucional en el principio de legalidad y tipicidad de la sanciones penales y administrativas contenido en el artículo 25.1 de la Constitución. En similar sentido se muestran las SSTC 66/1986, de 23 de mayo; 94/1986, de 8 de julio; 107/1989, de 8 de junio; 154/1990, de 15 de octubre; 234/1991, de 10 de diciembre; 204/ 1996, de 16 de diciembre; 221/1997, de 4 de diciembre; 2/2003, de 16 de enero; 229/2003, de 18 de diciembre; 188/2005 de 7 de julio; 334/2005, de 20 de diciembre; 48/2007, de 12 de marzo; 91/2008, de 21 de julio; también lo menciona la STS de 17 de marzo de 2009 (Ref. IUSTEL: \$289519). Vid. en el mismo sentido, ATC 239/2003 de 14 de julio; ATC 389/ 1988, de 24 de marzo; ATC 648/ 1988, de 23 de mayo ATC 277/2003, de 25 de julio; ATC 357/2003, de 10 de noviembre; ATC 141/2004, de 26 de abril; STC 180/2004, de 2 de noviembre.

${ }^{14}$ Del Rey Guanter, Salvador (2005), La potestad sancionadora de la administración y jurisdicción penal en el orden social, pp. 123-124; Alonso Más José María, Prevalencia de la vía jurisdiccional penal y prohibición del doble enjuiciamiento, Tirant lo Blanch, Valencia, pp. 25-26; Gómez Tomillo, Manuel, y Sanz Rubiales, Iñigo, Derecho administrativo sancionador, p. 206. Garberí Llobregat, José y Buitrón Ramírez Guadalupe (2008), El procedimiento administrativo sancionador, Vol. I, 5 a ed., Tirant lo Blanch, Valencia, p. 203; De León Villaba, Francisco Javier, Acumulación de sanciones penales y administrativas, p. 446; NAVARro Cardoso, Fernando, Infracción administrativa y delito: límites a la intervención del Derecho Penal, p. 36; LóPez BARJA De Quiroga, Jacobo (2004), Tratado de Derecho Procesal Penal, Aranzadi, Navarra, p. 402.
} 
la mexicana no estipulan de manera expresa en sus artículos 25 y 23 este principio, debiendo hacerlo el Tribunal Constitucional y la jurisprudencia en México, al considerar que incardinan reglas y valores asentados en la propia Constitución ${ }^{15}$.

El principio de proporcionalidad aparece con mayor frecuencia en la motivación de las decisiones del Tribunal Constitucional. Como señala la STC 154/1990, de 15 de octubre, su finalidad exige mantener una adecuación entre la gravedad de la infracción y la sanción impuesta, de tal manera que una vez que se aplica la determinada sanción a una específica infracción la reacción punitiva queda acotada, dicha reacción está en armonía y consonancia con la acción delictiva y, la correspondiente condena ha de considerarse autosuficiente desde una perspectiva punitiva, por lo que aplicar otra sanción en el mismo orden punitivo representaría la ruptura de esa pro-

\footnotetext{
${ }^{15}$ Vid. La STC 154/199o, de 15 de octubre, señala lo siguiente: Se impide sancionar doblemente por un mismo delito, desde la misma perspectiva de defensa social, o sea que por un mismo delito recaiga sobre un sujeto una sanción penal principal doble o plural, lo que también contradiría el principio de proporcionalidad entre la infracción y la sanción, que exige mantener una adecuación entre la gravedad de la sanción y la de la infracción; ATC 329/1995, de 11 de octubre, explica, para transgredir el nos bis in idem es indispensable

\begin{abstract}
la identidad fáctica de lo enjuiciado y que la condena tenga sustrato en una idéntica valoración jurídica; es decir, que se vuelva a valorar desde la misma perspectiva jurídica lo ya valorado. Expresando en otros términos: la interdicción que el principio supone no recae meramente sobre la sanción de los mismos hechos, que es el nervio escueto de los recurrentes, sino esencialmente sobre la sanción de la misma infracción. Detenerse en lo primero supondría negar la propia existencia del concurso ideal de delitos, con el correspondiente precio en términos de justicia, proporcionalidad y prevención; a evitar lo segundo -la reiteración punitiva por un mismo delitos tienden a las técnicas de resolución de concurso de leyes
\end{abstract}

en similar sentido la STC 180/2004, de 2 de noviembre. La jurisprudencia en México, establece que el principio de proporcionalidad debe perseguir una finalidad constitucionalmente legitima, ser adecuada, idónea, apta susceptible de alcanzar la finalidad perseguida por el legislador a través de la limitación respectiva, además debe ser necesaria, es decir, suficiente para alcanzar dicha finalidad de tal forma que no implique una carga desmedida e injustificada para el gobernado respectivo, así lo mencionó en la Novena época, Instancia: Pleno, Fuente: Semanario Judicial de la Federación y su Gaceta, Tomo: XXVI, diciembre de 2007, Jurisprudencia, Materia: Constitucional. Registro: 170740, p. 8; Tercera época, Instancia: Sala Superior del Tribunal Electoral, Fuente: Apéndice (actualización 2002), Tomo: VIII Jurisprudencia Electoral, Tesis 45, Registro: 922664, p. 63; en similar sentido se puede observar la Tesis aislada, Novena época, Instancia, Cuarto Tribunal Colegiado en Materia Administrativa del Primer Circuito, Fuente: Semanario Judicial de la Federación y su Gaceta, Tomo: XXII, septiembre de 2005, Registro: 177124, p. 1519. Por tanto, si se llegará a otorgar una sanción desproporcionada como sancionar dos veces a un sujeto por el mismo hecho y fundamento representaría la vulneración del principio non bis in idem. Vid. Cárdenas Rioseco, Raúl F. (2004), La prisión preventiva en México. Condena por adelantado o medida de seguridad encubierta, Porrúa, México, pp. 100-101; SÁNCHez GiL, Rubén (2009), "Recepción jurisprudencial del principio de proporcionalidad en México", en: Revista Mexicana de Derecho Constitucional, UNAM, México, núm. 21, p. 473. 
porcionalidad, con una conexión excesiva del ordenamiento jurídico al infligirse a una sanción desproporcionada respecto de la infracción que se ha cometido ${ }^{16}$.

Por otro lado el principio de proporcionalidad y, por ende, el non bis in idem están basados en la idea de justicia igual que corresponde a todo el ordenamiento jurídico ${ }^{17}$, ya que la proporcionalidad se entiende como la aplicación de una sanción más justa, la idea de justicia se da como consecuencia de las arbitrariedades de los poderes públicos frente a los ciudadanos, pero por sí sola no representa el fundamento del non bis in ídem, pues requiere de los otros principios para complementarse, es decir, coadyuva a impedir sancionar doble vez por un mismo ilícito a un sujeto en el que implique el mismo hecho y con idéntico fundamento, ya que este principio conlleva la prohibición del exceso, tanto en el sentido de otorgar una pena desproporcionada en cuanto lesione sus derechos, como también otorgar una pena que beneficie de más al ciudadano no correspondiente con la conducta ilícita, sino que en este caso merezca mayor sanción impuesta por la infracción cometida.

\footnotetext{
${ }^{16}$ Vid. Aradilla Marqués María José (2000), "Responsabilidad empresarial en orden a las prestaciones: últimos matices en la jurisprudencia”, en Aranzadi social, Aranzadi, núm. 19. (Ar. 200o/2034), pp. 9-12; DEL REY GUANTER, Salvador, La potestad sancionadora de la administración y jurisdicción penal en el orden social, pp. 123-124. Vid. la STS 23 de diciembre de 2008 (Ar. 376), la finalidad que se pretende es que la actuación de la Administración sea proporcionada con los fines que persigue. Para apreciarla deberá compararse la gravedad del hecho ilícito con la gravedad de la sanción, debiendo motivarlas para conocer cuál fue la razón de por qué se impuso una concreta sanción y no otra más leve o menos grave; en el mismo sentido las SSTS de 3 de diciembre de 2008 (Ar. 205); 7 de noviembre de 2007 (Ar. 1420); 6 de junio de 2007 (Ar. 3369); 20 de noviembre de 2007 (Ar. 667); 23 de marzo de 2005 (Ar. 2613); 2 de junio de 2003 (Ar. 4118); 24 de octubre de 2000 (Ar. 9375). Vid. sentencia del Tribunal Europeo de Derechos Humanos de 14 de diciembre de 2006 (TEDH 77), apuntó en términos semejantes que el principio proporcionalidad debe guardar una adecuación entre medios empleados y el fin perseguido. Vid. Bernal Pulido, Carlos (2007), El principio de proporcionalidad y los derechos fundamentales, $3^{\text {a }}$ ed. CENTRO DE Estudios Políticos y Constitucionales, Madrid, pp. 41-42; Rodríguez De Santiago, José María (20oo), La ponderación de bienes e intereses en el derecho administrativo, MARCIAL Pons, Barcelona, pp. 25 y 105-109; Sarmiento Ramírez-Escudero, Daniel (2004), El control de proporcionalidad de la actividad administrativa, Tirant Lo Blanch, Valencia, pp. 349-363 y Andrés Pérez, María del Rocío, (2008), El principio de proporcionalidad en el procedimiento administrativo sancionador, BOSCH, Barcelona, pp. 24-25.

17 Del Rey Guanter, Salvador, La potestad sancionadora de la administración y jurisdicción penal en el orden social, pp. 123-124. Por dicha causa se establece en el artículo 8 de la Declaración de los Derechos del Hombre y del Ciudadano de 1789 donde afirma que la ley no debe establecer otras penas que las estrictas y evidentemente necesarias. Se menciona con más claridad en el artículo 12 según el cual: la ley no debe señalar sino las penas estrictamente necesarias y proporcionadas al delito, como también se encuentra en infinidad de disposiciones, sólo por mencionar algunas el artículo 16 de la Constitución Francesa de 1973; el artículo 131.3 de la LRJPAC cuyo tenor es el siguiente: en la determinación normativa del régimen sancionador, así como en la imposición de sanciones por las Administraciones Públicas se deberá guardar la debida adecuación entre la gravedad del hecho constitutivo de la infracción y la sanción aplicada. Vid. los siguientes autores si se quiere profundizar más sobre la idea de justicia. Benlloch Petit, Guillermo, "El principio de non bis in idem en las relaciones entre el Derecho Penal y el Derecho disciplinario", en Revista del Poder Judicial, hace referencia a la idea de justicia en el sentido que representa un límite a la facultad de castigar, lo cual debe de ir acorde entre la gravedad del hecho y la intensidad de la sanción, p. 313; DE La MATA BARRAnCO, Norberto Javier (2007), El principio de proporcionalidad penal, Tirant lo Blanch, Valencia, p. 19; García Álvarez, Francisco Javier (2009), Sobre el principio de legalidad, Tirant lo Blanch, Valencia, pp. 103-118; Beccaria, Cesare (1983), De los delitos y las penas"(de las Casas, J. A. Traductor), Alianza, Buenos Aires, p. 138.
} 


\subsection{Principio de seguridad jurídica}

Para algunos autores el fundamento del non bis in idem se encuentra en el principio de seguridad jurídica, como se muestra a continuación ${ }^{18}$.

Se señala que el principio de proporcionalidad junto con el de seguridad jurídica justifican la garantía del non bis in idem, ya que cada uno de esos fundamentos por sí solos y por separado no permiten abarcar el total fundamento al que corresponde el principio ${ }^{19}$.

Otros autores apuntan que el principio de seguridad jurídica posiblemente sea el fundamental en atención a que habiendo sido ya castigada una persona en relación con unos mismos hechos y en atención a la lesión de determinado bien jurídico protegido, después no se puede reiterar la imposición de sanciones a la misma persona por la comisión de esos hechos y en atención a la infracción del mismo bien jurídico ${ }^{20}$. Una vez impuesta la primera sanción, no se debe volver a castigar, pues el sujeto tiene la certeza jurídica de no volver a ser castigado, en el sentido de que se ha agotado el ius puniendi del Estado, si esto sucediera, entonces se estaría infringiendo la seguridad jurídica ${ }^{21}$. El Tribunal Constitucional también se ha apoyado en el principio de seguridad jurídica para fundamentar la prohibición del bis in idem ${ }^{22}$, de igual forma se presenta en México ${ }^{23}$.

Lo que se busca evitar es la duplicidad de procedimientos y la doble valoración de un hecho, pues los mismos hechos no pueden existir y dejar de existir para los órganos del Estado, postura

\footnotetext{
${ }^{18}$ Navarro Cardoso, Fernando, Infracción administrativa y delito: límites a la intervención del Derecho Penal, p. 36; Garberí Llobregat, José y Buitrón Ramírez Guadalupe (2008), El procedimiento administrativo sancionador, Vol. I, $5^{\text {a }}$ ed. Tirant lo Blanch, Valencia, p. 206; Ruiz Robledo, Agustín (2003), El derecho fundamental a la legalidad punitiva, Tirant lo Blanch, Valencia, p. 283; Alonso Mas, María José, Prevalencia de la vía jurisdiccional penal y prohibición del doble enjuiciamiento, pp. 28-30; Entrena Ruiz, Daniel (2006), El empleo de información privilegiada en el mercado de valores: un estudio de su régimen administrativo sancionador, THомsonCivitas, Madrid, pp. 356-357; López Barja De Quiroga, Jacobo, "Tratado de Derecho Procesal Penal", p. 402.

${ }^{19}$ MuÑoz Lorente, José (2001), "La nueva configuración del principio non bis in idem. Las sanciones administrativas como límite a la intervención de la jurisdicción penal. Especial referencia al ámbito medioambiental”, Cuadernos profesionales de gestión ambiental, ECOIURIS LA LEY, Madrid, p. 52.

${ }^{20}$ Alonso Mas, María José, "Prevalencia de la vía jurisdiccional penal y prohibición del doble enjuiciamiento", pp. 28-29.

${ }^{21}$ Sobre el principio de seguridad jurídica véase Alonso MAs, María José, Prevalencia de la vía jurisdiccional penal y prohibición del doble enjuiciamiento, pp. 28-29; Gallardo Castillo, María Jesús (2008), Los principios de la potestad sancionadora. Teoría y práctica, IUSTEL, Madrid, p. 317. En similar sentido véase Bravo Bosch, María José (2016), Ne bis in ídem, en Revista General de Derecho Romano, IUSTEL, España, núm. 26.

${ }^{22}$ Así lo señala en esta STC 107/1989, de 8 de mayo, la aplicación de dicho principio supone, en lo que ahora importa, que las autoridades de un mismo orden, a través de procedimientos distintos, no pueda sancionar repetidamente una misma conducta ilícita, por entrañar esta duplicación de sanciones una inadmisible reiteración en el ejercicio del ius puniendi del Estado, de otro lado, el derecho de los ciudadanos a no ser sancionados sino en las condiciones establecidas por el art. 25.1 de la Constitución implica también que los mismos hechos enjuiciados por distintos órganos del Estado no puedan existir y dejar de existir al mismo tiempo, pues a ello se oponen no sólo elementales exigencias lógicas, sino también el principio general de seguridad jurídica que el art. 9.3 de la Constitución, pero hace referencia a este supuesto desde la sentencia 2/1981, de 30 de enero, más específico en la STC 77/1983, de 3 de octubre, en el mismo sentido. Vid. la SSTC 159/1985, de 27 de noviembre; 23/1986, de 14 de febrero; 94/1986 de 8 de julio; 107/1989, de 8 de 1989; ATC 26/2002, de 26 de febrero.

${ }^{23} \mathrm{El}$ non bis in idem tiene su fundamento en la idea de justicia material y para llegar a ella se auxilia de una serie de principios como son el de legalidad, proporcionalidad, seguridad jurídica y cosa juzgada como se muestra en la Novena época, Instancia: Cuarto Tribunal Colegiado en Materia Civil del Primer Circuito, Fuente: Semanario Judicial de la Federación y su Gaceta, Tomo: XXIX, febrero de 2009, Tesis 1.4 o.C36K, Materia Común, Tesis aislada, Registro: 167948, p. 1842; Novena época, Instancia: Primer Tribunal Colegiado en Metería Administrativa y Civil del Décimo Noveno Circuito, Fuente: Semanario Judicial de la Federación y su Gaceta, Tomo: XXXI febrero de 2010, Tesis XIXo.A.C.54C, Materia: Civil, Tesis aislada, Registro:165299, en esta Tesis se dice al respecto que 
que también mencionó el mismo Tribunal en la sentencia 77/1983, de 3 de octubre y en otras sentencias, donde confirma lo ya establecido por la anterior sentencia agregando la vulneración al principio de seguridad jurídica ${ }^{24}$.

\title{
3. Vinculación de la cosa juzgada con el principio "non bis in idem"
}

Otro sector de la doctrina destaca la vinculación del principio de seguridad jurídica con el de la cosa juzgada y éstos anclados, a su vez, al fundamento del principio non bis in idem, por ello volveré a enunciar un poco el tema anterior.

El principio de seguridad jurídica protege al ciudadano frente a una ulterior sanción y una nueva persecución punitiva que ha adquirido firmeza; es aquí donde se desempeña el papel de la cosa juzgada. Desde el origen del principio non bis in idem se relaciona con la cosa juzgada en sus dos aspectos: uno negativo y uno positivo; el primero se da con la imposibilidad de que se produzca un nuevo pronunciamiento sobre el tema y en el segundo, lo declarado por sentencia

la cosa juzgada, además de constituir la verdad legal para quienes fueron parte en el juicio, implica la imposibilidad de volver a discutir lo decidido, porque la rigidez o inmutabilidad de la sentencia definitiva descansa en los principios de seguridad y certeza jurídica, p. 2816. Luna CASTro, José Nieves (2006), La suprema Corte como órgano de legalidad y Tribunal Constitucional, Porrúa, México, menciona que el principio de seguridad jurídica está estrechamente vinculada con la existencia de un ordenamiento eficaz, congruente y justo, como presupuesto de un estado de derecho y consecuentemente bien común, pp. 92-97. Vid. BurgoA, Ignacio (2003), Las garantías individuales, $36^{\mathrm{a}}$ ed., Porrúa, México, pp. 504-505.

${ }^{24}$ STC 24/1984, de 23 de febrero, apunta que:

\begin{abstract}
en la realidad jurídica, esto es, en la realidad histórica relevante para el Derecho, no puede admitirse que algo es y no es, que unos mismos hechos ocurrieron y no ocurrieron, o, por decirlo en los términos del fundamento jurídico 6 de nuestra Sentencia de 3 de octubre de 1983, es claro que unos mismos hechos no pueden existir y dejar de existir para los órganos del Estado, pues a ello se oponen no sólo principios elementales de la lógica jurídica y extrajurídica, sino el principio de seguridad jurídica constitucionalizado en el art. 9.3. Ante situaciones hipotéticamente de esta índole el Tribunal Constitucional no siempre tendrá competencia para intervenir sin más; por el contrario, habrá que comprobar, $y$ así lo haremos en este caso, en primer término, si en verdad se produce entre las resoluciones enfrentadas una estricta identidad en los hechos y en segundo lugar si hay en juego algún derecho fundamental afectado por la contradicción fáctica, pues la invocación del solo principio de seguridad jurídica no es, obviamente, base para conocer en amparo,
\end{abstract}

esto lo dice porque tales principios por sí solos no procrean derechos fundamentales, así se observa en el ATC 211/1983 y en el mismo sentido, ATC 333/1983, como en la sentencia 10/1985 de, 28 de enero de 1985, Es manifiesto que en el art. 9.3 de la CE no se genera un derecho fundamental susceptible de protección en vía de amparo, ni la interpretación que los Tribunales llevan a cabo de las normas sobre prescripción de acciones y derechos es materia sobre la que este Tribunal haya de pronunciarse, siempre que por dicha vía no quede menoscabado un derecho de carácter fundamental. 
firme, constituye la verdad jurídica ${ }^{25}$. La jurisprudencia también menciona que el efecto de la cosa juzgada sólo se predica respecto de resoluciones judiciales firmes ${ }^{26}$.

La cosa juzgada presenta dos manifestaciones: una formal y otra material. La primera se refiere a aquella que implica la imposibilidad que una determinada decisión sea recurrida, es decir, la improcedencia o cierre de los recursos procesales contra ésta; la cosa juzgada material, se refiere al efecto que produce respecto de otros procesos, es decir, se proyecta de forma positiva, (vinculante o prejudicial), lo que determina que el juzgador futuro debe respetar el contenido de lo juzgado en un proceso precedente para evitar caer en contradicciones; su función negativa, o también denominada excluyente o preclusivo, supone que el proceso posterior deberá abstenerse de enjuiciar los hechos que ya fueron materia de juicio en el primer proceso. Esta función aparece recogida en el artículo 222.1 Ley de Enjuiciamiento Civil ${ }^{27}$.

El principio de seguridad jurídica rige todo Estado de Derecho y éste a su vez impone que cuando acontezca un conflicto y se llegue a la sentencia del mismo a través de ella se adquiera

${ }^{25}$ En el mismo sentido Del Rey GuAnter, Salvador, La Potestad sancionadora de la administración y jurisdicción penal en el orden social, pp. 79-80; en términos similares también se expresa DE LA Oliva SANTos (1991), Andrés, Sobre la cosa juzgada. Civil, Contencioso-Administrativa y Penal, con examen de la jurisprudencia del Tribunal Constitucional, Centro de Estudios Ramón Areces, Madrid, pp. 19-27. En la sentencia 77/1983, de 3 de octubre, se establece también el sentido positivo y negativo de la cosa juzgada así como que la misma debe ser respetada. El instituto de la cosa juzgada tiene por premisa principal evitar la reproducción indeterminada de litigios con el fin de conseguir la estabilidad jurídica no volviendo a juzgar sobre lo ya juzgado en sentencia firme. En sentido semejante la Audiencia Provincial de Santa Cruz de Tenerife 102/2001, de 3 de febrero (Ar. 134136). Vid. CALAzA López, Sonia, "El alcance virtual de la cosa juzgada material", en: Actualidad Jurídica Aranzadi, Aranzadi, España, núm. 773, 2009, establece que la cosa juzgada tiene un objetivo principal la erradicación de la masiva interposición de demandas, que, formuladas desde diversas perspectivas puntos de vista o ángulos jurídicos con el oculto, y en cierto modo, fraudulento, propósito de obtener una respuesta favorable a sus pretensiones y que no tuvieron en el proceso anterior, tratan en verdad, de burlar el instituto de la cosa juzgada. p. 2. Véase BonACHERA Villegas, Raquel (2015), Sobre preclusión y excepción de la cosa juzgada, en: Revista General de Derecho Procesal, IUSTEL, España, núm. 37.

${ }^{26}$ Así lo expresa de manera literal la STC 159/1987, de 26 de octubre, [...], el respeto a la firmeza de esas resoluciones judiciales y a la intangibilidad de las situaciones jurídicas en ellas declaradas [...], pues también si la cosa juzgada material fuese desconocida vendría a privarse de eficacia a lo que se decidió con firmeza al cabo del proceso; en el mismo sentido la STC 91/2008, de 21 de julio, menciona: Ello implica la imposibilidad de proceder a un nuevo enjuiciamiento penal si el primer proceso ha concluido con una resolución de fondo con efecto de cosa juzgada, ya que, en el ámbito de lo definitivamente resuelto por un órgano judicial, dispensado por la anterior decisión firme y se arroja sobre el reo la carga y la gravosidad de un nuevo enjuiciamiento; en igual sentido pero con grados variables de expresividad se presentan las SSTC 23/2008 de 11 de febrero; 218/2007, de 8 de octubre; 229/2003, de 18 de diciembre; $2 / 2003$, de 16 de enero; 16o/2002, de 16 de septiembre; 15/2002, de 28 de enero; 58/200o, de 28 de febrero; 222/1997, de 4 de diciembre; 242/1992, de 21 de diciembre.

${ }^{27}$ En otras palabras, una resolución judicial que goza de cosa juzgada no puede ser objeto de más recursos. Sus efectos se producen exclusivamente en el proceso en que se ha dictado la sentencia, por lo que se considera precaria (es la resolución que termina un proceso y no es recurrible, por tanto, adquirirá firmeza y valor de cosa juzgada formal); la cosa juzgada material es aquella que implica la inacatabilidad de un resultado procesal mediante el inicio de un nuevo juicio, al cerrarse toda posibilidad de que se emita una decisión que se contradiga o se oponga a la resolución judicial firme dictada. La STS de 18 de noviembre de 1997 (Ar. 1022) alude:

\footnotetext{
siendo la cosa juzgada formal el efecto de la sentencia que ha ganado firmeza, la cosa juzgada material es el estado jurídico de una cuestión sobre la que ha recaído la sentencia firme (con autoridad de cosa juzgada formal), que tiene la eficacia de vincular al órgano jurisdiccional en otro proceso. Esta eficacia es negativa o excluyente, cuando se repite la misma cuestión y en este otro proceso no se entra al fondo por acogerse la cosa juzgada como excepción. Y la eficacia es positiva o prejudicial cuando dicha cuestión no es el objeto único del otro proceso, sino que forma parte de éste, en cuyo caso la sentencia que recaiga deberá tener como punto de partida y en ningún caso contradecir lo resuelto en la anterior sentencia.
}

Vid. De La Oliva Santos, Andrés, Sobre la cosa juzgada. Civil, Contencioso-Administrativa y Penal, con examen de la jurisprudencia del Tribunal Constitucional, pp. 19-27; Aradilla Marqués, María José., "La función positiva 
la fuerza de la denominada cosa juzgada material y, que extienda sus efectos fuera del proceso otorgando no sólo firmeza a lo declarado, sino haciéndolo vinculante para el futuro e impidiendo, en consecuencia, que el ciudadano se vea expuesto a un nuevo enjuiciamiento por el mismo hecho $^{28}$, ya que si sucediera lo contrario se estaría transgrediendo el principio de seguridad jurídica generando una grave inseguridad jurídica a los ciudadanos. Por su parte DE LEÓN VILLABA, dice que la seguridad jurídica influye en la estructura formal de Derecho y, deja sentir sus efectos, principalmente, en su vertiente procedimental; además la traslación de esta idea al procedimiento ya sea administrativo o penal, se traduce en una serie de principios y aplicación del Derecho tendencialmente inspiradas por la certeza. Y en este contexto es fácil aprehender la relación entre dicho principio y el instituto de la cosa juzgada ${ }^{29}$.

Asimismo dicho autor establece sus dudas entre la vinculación de la cosa juzgada material y el principio non bis in idem. En el aspecto procesal la dificultad radica en que el efecto de la cosa juzgada no puede predicarse siempre respecto de la resolución administrativa y sólo sí en sentido estricto de las resoluciones judiciales, por consiguiente, la cosa juzgada no puede garantizar el non bis in idem ${ }^{30}$. En ese sentido se afirma que la cosa juzgada es un instrumento procesal

de la cosa juzgada: determinación de la contingencia de una capacidad permanente mediante proceso previo sobre incapacidad temporal" en: Aranzadi Social, Aranzadi, España, núm. 7, 2008, alude a los dos aspectos de la cosa juzgada (negativo y positivo) el positivo refiere a la parte subjetiva (identidad de partes) de los procesos relacionados por la cosa juzgada, en esencia las partes del segundo proceso (24.4 Ley de Enjuiciamiento Civil); el afectado por la vinculación haya sido también parte del primero en el que se haya dictado sentencia cuya vinculación se señala, aparte se requiere cierto grado de identidad objetiva res de qua agitur (cosa de que se trata) en efecto, resulta obvio que los procesos no son idénticos con exactitud pero los principales elementos sí lo son. pp. 1-7; PAredes Rodríguez, José Miguel (2007), La cosa juzgada en materia de seguridad social, en: Aranzadi Social, Aranzadi, España, núm. 20, señala que no es suficiente con comparar el petitum (como lo enunciaba el artículo derogado 1252 del Código Civil) sino que además es necesario examinar lo expresamente concedido o vedado en la sentencia firme del proceso anterior. pp. 4-10; Palacio Arantzazu Vicente (20o8), "Efecto positivo de la cosa juzgada en el proceso laboral”, en: Cuadernos de Aranzadi Social, Arazandi, España, núm. 28, pp. 2-54; Zapirain Bilbao, Ana (2007), "Las implicaciones de la cosa juzgada en los litigios sobre Seguridad Social. Reflexiones al hilo de la más reciente jurisprudencia del TS”, en: Aranzadi Social, Aranzadi, España, núm. 4, pp. 3-6. En México la jurisprudencia se pronuncia en el mismo sentido, así se puede observar la tesis aislada de rubro cosa juzgada material y formal en sede de amparo, con registro 214661 , en la cual se menciona que respecto de la primera la denomina indiscutibilidad o non bis in ídem, y en cuanto a la segunda como irrecurribilidad del acto.

${ }^{28}$ López Barga De Quiroja, Jacobo (2004), El principio non bis in ídem, en Cuadernos de L. Jiménez de Asua, DYKINSON, Madrid, núm. 19, para este autor su fundamento del principio non bis in idem, no se encuentra en la cosa juzgada, sino en el principio de culpabilidad y el de seguridad jurídica, el principio de culpabilidad, impide que pueda imponerse por el mismo hecho al mismo sujeto una sanción que exceda del límite proporcional a la culpabilidad, y en cuanto a la seguridad jurídica considera que no es admisible en un Estado de Derecho la amenaza permanente de las diferentes sanciones (simultáneas o sucesivas en el tiempo) por el mismo hecho al mismo sujeto, pues, además, tal consideración entraña someter al ciudadano un trato inhumano. Cuestión en la que no se está de acuerdo por las siguientes causas: de ningún modo se debe fundamentar el principio non bis in idem en el principio de culpabilidad, dado que no sólo se aplica en cuestiones de índole penal sino también administrativo sancionador; las bases de la culpabilidad no son muy sólidas para establecer el reproche que se hace a una persona, porque ésta debió actuar de modo distinto a como lo hizo y determinar los márgenes del deber no resulta fácil, así como el grado en que opera o no la exigencia de culpabilidad, lo que ocasionaría variadas confusiones a la hora de aplicar el non bis in idem. pp. 20-57.

${ }^{29}$ De León Villalba, Francisco Javier, Acumulación de sanciones penas y administrativas, pp. 437-438.

${ }^{30}$ EL ATC. $277 / 2003$, de 25 de julio, establece que la cosa juzgada no es un requisito necesario para la producción del non bis in idem, y lo expresa de la siguiente manera:

la garantía del non bis in idem se configura en un derecho fundamental, que, en su vertiente material impide sancionar en más de una ocasión el mismo hecho con el mismo fundamento, de modo que la reiteración sancionadora constitucionalmente proscrita puede producirse mediante la sustanciación de una dualidad de procedimientos sancionadores, abstracción hecha de su naturaleza penal o administrativa, y en el seno de un único procedimiento, de ello deriva la falta de reconocimiento del efecto de la cosa juzgada. 
para garantizar la prohibición del "non bis in idem", sin que quepa una identificación absoluta entre ambas instituciones, pues ni la cosa juzgada es el único instrumento de garantía de dicha prohibición ni aquélla persigue únicamente garantizar la referida prohibición ${ }^{31}$. El principio en cuestión no se puede fundamentar en la cosa juzgada, ya que puede suceder que la Administración imponga previamente una sanción que no sea recurrida y ésta deviene firme, en este supuesto no opera la cosa juzgada ${ }^{32}$.

Se menciona además que el principio non bis in idem constituye el efecto negativo de la cosa juzgada determinando la inadmisibilidad de la pretensión ya formulada en un proceso anterior, siempre que exista una identidad de los elementos de la decidida y de los que se intenta hacer valer de nuevo, pues esa circunstancia comporta la identificación de las pretensiones mismas ${ }^{33}$.

Hay quienes apuntan que la prohibición de la duplicidad sancionadora no puede tener como fundamento la cosa juzgada y máxime que también implica duplicidad de enjuiciamiento ${ }^{34}$. Para Nieto, el conectar el non bis in idem con la cosa juzgada carece, en definitiva de justificación dogmática y en modo alguno viene impuesta por el Derecho positivo; agrega otra explicación de carácter finalista, es decir que si gracias a esta figura se pudiera manejar con certeza el

Hace referencia a lo mismo la STC 180/2004, de, 21 de diciembre.

${ }^{31}$ Cano Campos, Tomás, Non bis in idem..., p. 201. La cosa juzgada material sí tiene una vinculación con el non bis in idem y con razón propugna STS de 19 de junio de 1998 (Ar. 601), donde se enuncia la cosa juzgada que establece el artículo 1.252 CC es la denominada cosa juzgada material, que puede contemplarse desde una distinta vertiente; una, negativa plasmada en el principio jurídico non bis in idem, que no permite que una contienda judicial ya dilucidada por sentencia firme pueda volver de nuevo a plasmarse; y la otra, positiva es derivada de la obligación que tiene el juzgador de seguir absolutamente lo declarado en otro proceso anterior, cuando versen ambos sobre la misma controversia judicial, en el mismo sentido, SSTS de 3 de abril de 1990 (Ar. 2693); 1de octubre de 1991 (Ar. 7439);31 de marzo de 1992(Ar. 2315); 27 de diciembre de 1993(Ar. 10153) y de 20 de septiembre de 1996/Ar. 6727). Como afirma Gallardo Castillo, María Jesús, Los principios de la potestad sancionadora..., la cosa juzgada, se entiende como excepción procesal por virtud de la cual no resulta admisible un nuevo enjuiciamiento cuando concurra la más perfecta identidad entre cosas, las causas, las personas de los litigantes y la calidad con que lo fueron, en el bien entendido que integran la causa de pedir aquellos hechos expuestos por las partes que estén contemplados en la norma como productores de la consecuencia jurídica pretendía, p. 307.

32 Cano Campos, Tomás, Non bis in idem..., p. 201.

33 Tr ayter, Joan Manuel, Manual de derecho disciplinario de los funcionarios públicos, p. 222. En el mismo sentido lo establece Garcia Planas G. "Consecuencias del principio non bis in idem en el Derecho penal”, en: Anuario de Derecho Penal y Ciencias Penales fascículo I enero-abril, 1989, apunta si bien el principio non bis in idem no se halla regulado de una manera expresa en la Ley de Enjuiciamiento Criminal, debe considerarse incluido dentro del concepto de cosa juzgada; pues nadie puede ser juzgado dos veces por la comisión de un hecho delictivo. Dicho autor establece su fundamento en la STC 66/1986, de 23 de mayo de 1986, donde afirma el Tribunal Constitucional que nadie puede ser juzgado dos veces por la comisión de un mismo hecho delictivo a menos de que se trate de procedimientos distintos y por hechos diferentes, pp. 111-112.

34 Alonso Mas, María José, Prevalencia de la vía jurisdiccional penal y prohibición del doble enjuiciamiento", menciona que una sanción administrativa firme pero no recurrida no produce cosa juzgada. Si la cosa juzgada fuera el fundamento de la prohibición que nos ocupa, no podría jugar en casos como éste, y sería de plano errónea, si mayor argumentación, la consideración de que, tras la firmeza de una sanción administrativa firme pero no recurrida, no cabe sanción penal y tiene como base la STC 112/1990, de 18 de julio, en ésta se enuncia que sólo puede conculcarse la prohibición del non bis in idem una vez que recaiga sanción administrativa firme, ya que de lo contrario podría ser anulada. Indica además que la cosa juzgada tiene un alcance más amplio que la materia abordada. La autora agrega que tanto la cosa juzgada como la prohibición de duplicidad en el ámbito sancionador tienen una misma base en común que es la seguridad jurídica, p. 33. GAllardo CAstillo, María Jesús, Los principios de la potestad sancionadora Teoría y práctica, señala un gran problema cuando la resolución administrativa es impugnada ante la Jurisdicción contenciosa-administrativa, posibilidad que queda incólume si la persona que ha resultado sancionada desea ante esta jurisdicción manifestar su disconformidad con la sanción impuesta; revisada la sanción por la jurisdicción contencioso-administrativa desaparece la pretendida prevalencia de la resolución penal, pues lo que se produce es un eventual conflicto entre dos jurisdicciones, p. 313. 
fruto del non bis in idem; respuesta que es negativa, la conclusión a la que llega el autor citado es la siguiente:

El Derecho Administrativo Sancionador necesariamente ha de elaborar en este punto una doctrina propia aunque se encuentre inicialmente inspirada por la estructura propia de la cosa juzgada, dogmática que habría de girar fundamentalmente en torno a las figuras concursales $y$ sobre el análisis y contraste de los hechos constitutivos de los ilícitos, de los sujetos y de los bienes protegidos por las normas, sin olvidar el distanciamiento de las técnicas procesales es tanto más necesario cuanto que el Derecho Administrativo Sancionador el non bis in idem opera incluso para dos sanciones administrativas, es decir, sin que medie sentencia ni cosa juzgada ${ }^{35}$.

Por tanto, el non bis in idem no tiene su fundamento en la cosa juzgada, pero sí es un elemento procesal que garantiza el principio. En el aspecto administrativo sancionador en ocasiones no existe cosa juzgada, sino sólo un acto administrativo firme, por consiguiente, el principio en cuestión no sólo hace referencia en materia penal, también en materia administrativa, en el que la cosa juzgada no siempre opera. En los supuestos en que se esté ante la Sala de lo Contencioso-administrativo, donde si puede operar la cosa juzgada puesto que se encuentran ante dos jurisdicciones diferentes una penal y otra administrativa. Uno de los problemas en México es que el non bis in idem se tienden a relacionar sólo con la materia penal y ésta anclada a la cosa juzgada, como se vio con antelación, siendo que este principio rige no sólo para esta materia, sino también para la administrativa, procesal, laboral, penal y civil.

La doctrina y la jurisprudencia muestran una diversidad de dilemas sobre el non bis in idem incluyendo la cosa juzgada como fundamento, pero ésta es una figura jurídica que otorga garantía a dicho principio sin embargo no forma parte de su fundamento, ya que se conforma por los principios de legalidad, proporcionalidad y seguridad jurídica, todos ellos anclados entre si proporcionan al non bis in idem su fundamento.

\section{Abreviaturas}

VID. Véase

LOPJ. Ley Orgánica del Poder Judicial

Dir. Director.

SSTS. Sentencias del Tribunal Supremo

REF. Referencia.

ED. Edición

LOTC. Ley Orgánica del Tribunal Constitucional.

ATC. Audiencias del Tribunal Constitucional.

STC. Sentencia del Tribunal Constitucional.

STS. Sentencia del Tribunal Supremo.

TSJ. Tribunal Supremo de Justicia.

AP. Audiencia Provincial.

CE. Constitución Española.

CIT. Cita

PP. Páginas

TEDH. Tribunal Europeo de Derechos Humanos.

LRJPAC. Ley de Régimen Jurídico de las Administraciones Públicas y del Procedimiento Ad-

$\overline{35}$ Nieto, Alejandro, Derecho administrativo sancionador, pp. 434-435. 
ministrativo Común.

AR. Aranzadi.

TS. Tribunal Supremo

\section{Bibliografía}

Alonso Mas José María (2005), Prevalencia de la vía jurisdiccional penal y prohibición del doble enjuiciamiento, Tirant lo Blanch, Valencia.

Aradilla Marqués, María José (2008), “La función positiva de la cosa juzgada: determinación de la contingencia de una capacidad permanente mediante proceso previo sobre incapacidad temporal” en: Aranzadi Social, Aranzadi, España, núm. 7.

Andrés PÉRez, María del Rocío (2008), El principio de proporcionalidad en el procedimiento administrativo sancionador, BOSCH, Barcelona.

Aradilla Marqués, María José (2008), "La función positiva de la cosa juzgada: determinación de la contingencia de una capacidad permanente mediante proceso previo sobre incapacidad temporal" en: Aranzadi Social, Aranzadi, España, núm. 7.

Benlloch Petit, Guillermo (1998), "El principio de non bis in idem en las relaciones entre el Derecho Penal y el Derecho disciplinario", en: Revista del Poder Judicial, Consejo General del Poder Judicial, España, núm. 51.

Bernal Pulido, Carlos (2007), El principio de proporcionalidad y los derechos fundamentales, $3^{\text {a }}$. ed. De Estudios Políticos y Constitucionales, Madrid.

Beccaria, Cesare (1983), De los delitos y las penas, (de las Casas, J. A. Traductor), Buenos Aires, Alianza.

Bravo Bosch, María José (2016), "Ne bis in ídem”, en Revista General de Derecho Romano, IUSTEL, España, núm. 26.

Bonachera Villegas, Raquel (2015), Sobre preclusión y excepción de la cosa juzgada», en Revista General de Derecho Procesal, IUSTEL, España, núm. 37.

Burgoa, Ignacio (2003), Las garantías individuales, 36ª ed., Porrúa, México.

Cárdenas Rioseco, Raúl F. (2004), La prisión preventiva en México. Condena por adelantado o medida de seguridad encubierta, PorrúA, MÉxico.

Calaza López, Sonia (2009), "El alcance virtual de la cosa juzgada material”, en Actualidad Jurídica Aranzadi, Aranzadi, España, núm. 773.

Cano Campos Tomás (2003), "La suspensión de las autorizaciones administrativas para conducir en las infracciones sancionadas por autoridades distintas de las del Estado", en Revista Española de Derecho Administrativo, Civitas, Madrid, núm. 120.

De La Mata Barranco, Norberto Javiern (2007), El principio de proporcionalidad penal, Tirant lo Blanch, Valencia. 
De León Villalba, Francisco Javier (1998), Acumulación de sanciones penales y administrativas, BOSCH, Barcelona.

De La Oliva Santos, Andrés (1991), Sobre la cosa juzgada. Civil, Contencioso-Administrativay Penal, con examen de la jurisprudencia del Tribunal Constitucional, Centro De Estudios Ramón Areces, Madrid.

Del Rey Guanter, Salvador (1990), Potestad sancionadora de la Administración y jurisdicción penal en el orden social, Ministerio de Trabajo y Seguridad Social, Madrid.

Díaz Pita, María Del Mar (2002), "Informe sobre el principio non bis in idem y la concurrencia de jurisdicciones entre los Tribunales Penales Españoles y los Tribunales Penales Internacionales", en: Revue International de Droit Pénal, núm. correspondiente al $3^{\circ} \mathrm{y}$ $4^{\circ}$ trimestre.

Entrena Ruiz, Daniel (2006), El empleo de información privilegiada en el mercado de valores: un estudio de su régimen administrativo sancionador, THOMSON-CIVITAS, Madrid.

Gallardo Castillo, María Jesús (2008), Los principios de la potestad sancionadora. Teoría y práctica, IUSTEL, Madrid.

Garcia De Enterria, Eduardo, y Fernández Rodríguez, Tomás Ramón (2006), Curso de derecho administrativo, Tomo I, $13^{\text {a }}$ ed. CIZUR MENOR, CIVITAS, Pamplona.

Garcia De Enterria, Eduardo (2006), La constitución como norma y el tribunal constitucional, 4 ed. Arzandi, Madrid.

García Álvarez, Francisco Javier (2009), Sobre el principio de legalidad, Tirant lo Blanch, Valencia.

García Albero, Ramón (1995), Non bis in idem material y concurso de leyes penales, CEDECS, Barcelona.

Garcia Planas, Gabriel (1989), "Consecuencias del principio non bis in idem en el Derecho penal”, en Anuario de Derecho Penal y Ciencias Penales fascículo I enero-abril.

Garberí Llobregat, José, y BUitrón RAmírez Guadalupe (2008), El procedimiento administrativo sancionador, Vol. I y Vol., II $5^{\text {a }}$ ed., Tirant Lo Blanch, Valencia.

Gómez Tomillo, Manuel, y Sanz Rubiales, Iñigo (2010), Derecho administrativo sancionador, $2^{\mathrm{a}}$ ed., Aranzadi, Madrid.

González Pérez, José, y González Navarro, Francisco (2007), Comentarios a la Ley de Régimen Jurídico de las Administraciones Públicas y del Procedimiento Administrativo Común, vol. II, $3^{\mathrm{a}}$ y $4^{\mathrm{a}}$ ed. Civitas, Madrid.

LASCURAín SÁnChEz, Juan Antonio (2009), “Sólo penas legales, precisas y previas: El derecho a la legalidad penal en la jurisprudencia constitucional”, en Cuadernos Aranzadi del Tribunal Constitucional, Aranzadi, España, núm. 23. 
Lozano SuÁrez, L. M. (2005), "El principio non bis in idem: Colisión entre derecho penal y derecho administrativo sancionador", en: Revista de Derecho Penal, LEX NOVA, España, núm. 15.

López Barja De Quiroja, Jacobo (2004), Tratado de Derecho Procesal Penal, Aranzadi, Navarra.

Luna Castro, José Nieves (2006), La suprema Corte como órgano de legalidad y Tribunal Constitucional, Porrúa, México.

MuÑoz LoRente, José (2001), La nueva configuración del principio non bis in idem. Las sanciones administrativas como límite a la intervención de la jurisdicción penal. Especial referencia al ámbito medioambiental, Cuadernos profesionales de gestión ambiental, ECOIURIS, LA LEY, Madrid.

Nieto, Alejandro (2012), Derecho administrativo sancionador, $5^{\text {a }}$ ed. Tecnos, Madrid.

Navarro Cardoso, Fernando (2001), Infracción administrativa y delito: límites a la intervención del Derecho penal, COLEX, Madrid.

Paredes Rodríguez, J. M. (2007), “La cosa juzgada en materia de seguridad social”, en Aranzadi Social, núm. 20.

Palacio, arantzazu Vicente (2008), "Efecto positivo de la cosa juzgada en el proceso laboral”, en: Cuadernos de Aranzadi Social, ARANZADI, España, núm. 28.

Rodríguez De Santiago, José María (2000), La ponderación de bienes e intereses en el derecho administrativo, Marcial Pons, Barcelona.

Ruiz Robledo, Agustín (2003), El derecho fundamental a la legalidad punitiva, Tirant lo Blanch, Valencia.

SÁNCHEZ GIL, Rubén (2009), “Recepción jurisprudencial del principio de proporcionalidad en México”, en: Revista Mexicana de Derecho Constitucional, UNAM, México, núm. 21.

SALÁs Darrocha, Josep Tomás (2005), "Derecho fundamental a la legalidad penal: Jurisprudencia Constitucional y consideraciones críticas”, en Sentencias del TSJ Y AP y otros Tribunales, núm. 10.

SARmiento Ramírez-Escudero, Daniel (2004), El control de proporcionalidad de la actividad administrativa, Tirant lo Blanch, Valencia.

SuAy Rincón, José (1989), Sanciones administrativas, Publicaciones del Real Colegio de España, Bolonia.

Trayter, José Manuel, Manual de derecho disciplinario de los funcionarios públicos, Marcial Pons, Madrid, 1992.

Zugaldia Espinar (2004), José Miguel, El Derecho penal. Parte general, Tirant lo Blanch, Valencia. 
Pulido Quecedo, Manuel (2009.), "Lex certa, sanciones administrativas y remisiones legales”, en: Revista Aranzadi Doctrinal, Aranzadi, España, núm. 4.

Zapirain BilbaO, Ana (2007), "Las implicaciones de la cosa juzgada en los litigios sobre Seguridad Social. Reflexiones al hilo de la más reciente jurisprudencia del TS”, en Aranzadi Social, Arazadi, España, núm. 4. 